\title{
Türkiye'de Halk Hekimliği Uygulama Alanında İki Ekol: Şifacılar ve Hekimler
}

\author{
Two Schools in the Area of Folk Medicine Practice in \\ Turkey: Healers and Physicians
}

\section{Hicran Karataş*}

$\ddot{O} z$

Folklor disiplini bağlamında halk hekimliği halkın sağlık alanında hastalık, sağaltma, sağalmayla ilgili geliştirdiği, naklettiği bilgidir. Yerel ve özgün sağaltma yöntemleri pozitif bilimlerce geleneksel tıp (GT) şeklinde adlandırılmaktadır. Bu adlandırma, geçmişten günümüze ulaşan, deneyimlenmiş sağaltma metotlarından, modern tıp ilminin içeriğiyle, prensipleriyle çatışmayanlar için tercihen kullanılır. $\mathrm{Bu}$ nedenle geleneksel tıp kavramı, halk hekimliği bilgisinin kapsamı ve içeriği bakımından kuşatıcı değildir. Faydası deneyimlenmiş bu uygulamalar dünyada ve ülkemizde iki ekolde yetişenlerce icra edilir: Şifacılar ve hekimler. Sağlık Bakanlığı'nın 2014 yönetmeliğiyle belirli halk hekimliği uygulamalarını icra ruhsatı, hekimler ve diş hekimlerine tanınmıştır. Takip eden süreçte, uygulama alanında alaylı ve mektepli tartışmaları başlamıştır. Bu araştırmada Ankara'da kupa terapisi/hacamat uygulamalarını icra eden alaylılar ve mekteplilerin, onların hastalarının söz konusu uygulamaya yaklaşımları derleme yöntemiyle kaydedildi. Bir sağaltma yöntemi olarak hacamatın alaylılar ve mektepliler tarafından nasıl tatbik edildiği, uygulamanın halk bilgisindeki özgün haliyle ne kadar örtüştüğü,

* Dr., Öğretim üyesi, Bartın Üniversitesi Edebiyat Fakültesi. karatashicran@gmail.com. ORCID 0000.0002-4134-9150 / CC BY 
halkın deneyimsel bilgisinin deneyle doğrulanıp, doğrulanamadığı üzerinde durulmaktadır.

Anahtar sözcükler: folklor, Türk halk hekimliği, geleneksel tıp, kupa terapisi, hacamat, alayll,

\begin{abstract}
In the context of folklore discipline, folk medicine is the knowledge related to illness and to recover that has been enhanced throughout the ages and verbally transferred to generations in the area of health. Local and authentic healing methods of folk medicine are coined under the name of traditional medicine (TM) in the eyes of positive sciences. Modern medical scholars preferably use this very nomenclature to address particular folk knowledge formed in healing area that are handed down throughout generations, have been seen helpful and curative with self-experience, and do not directly conflict with both content and basic principles of modern medical scholarship. For this reason, the concept of traditional medicine does not embrace wholly all folk medicine knowledge which is more extensive and contentful. The beneficial and experienced practices in folk medicine have been performed in our country as well as the world by two schools: Healers and physicians. The license to practice in the area of TM has been given to physicians and dentists by the code that issued in 2014 by Republic of Turkey Ministry of Health. After this regulation, a discussion and competition has started in the area of practice between schools. In this study approaches of the practitioners from both parties and the view of their patients related to healing process have been compilated. How the cupping therapy is practiced by self-trained healers and medical scholars as a healing method and how much this very practice coincided with the original form of folk are questioned as well. The question of whether the cupping therapy as originally formed among folk is really beneficial, and folk's experiential knowledge has been verified by experiments have also been looked closer.
\end{abstract}

Keywords: folklore, folk medicine, traditional medicine, cupping theraphy, selftaught healers, physicians

\title{
Extended summary
}

Folklore is the folk knowledge that has been formed and developed by folk itself, and transmitted to generations through verbal, written and visual channels. Folk medicine comprises one part of this wholeness which focuses on health, illness, healing and cure. This very area covers all applications, methods, medicines and beliefs as well as theoretical lore. Local and authentic healing techniques of a particular society are nomenclature traditional medicine (TM) in the eyes of positive scholarship. This very term preferably and only is used for healing methods which have been proved by experiment. For this reason, we can attest that the folk medicine which is in conflict with content or principles of modern medicine, and whose benefits haven't been proven by experimentation simply are leaved 
out in the scope of TM. That is to say, TM term is not inclusive in terms of the scope and content of folk medicine which we refuse to separate it as experiential and experimental. Supposing that is possible, there are many practices which have been proved as useful are waiting to be experimented. Complementary and alternative medicine, on the other hand, are medicine methods and practices whose sources are completely foreign, and imported from one culture to another culture which always known as foreign in practice. Health lore in folk medicine diversifies and enlarges in parallel with locality and relativity. Its aim is both to protect society from illness, and to cure them from illness by means of material and spiritual means. This ensures the continuity of its' practice in addition to/or despite the formal health services. This is also because folk medicine services are alternative centers that enable folk to access health services in one way or another. It eases the formal health care services' burden as well. By doing so, it also promotes social endurance. Furthermore, folk medicine facilitates contact vernacular in between health care givers and takers, and is far from all time-consuming bureaucratic formalities. In this context, after a folk medicine practice became experienced in terms of its' benefits, it is performed in the application area without being stuck in the procedures. Nowadays, health practices transferred from folk medicine into TM are performed by practitioners who encultured in two different schools: Traditional healers and physicians. Earliest records about Turkish-Islamic civilization show that these schools were simultaneously active in the field of application in the past. Schools must have created expertise areas in certain practices and developed an understanding which required to be meticulous not to operate in each other's fields during republican period. With the regulation issued by Republic of Turkey of Ministry of Health in 2014 that practice license in TM limited with only physicians and dentists. This regulation generated a heated debate and competion between schools those healers became master in the pattern of masterapprenticeship and college educated physicians. Cupping therapy was one of healing methods which has been practiced by both physicians and self-trained healers before the regulation. Traditional healers are banned to practice cupping therapy, which also has been defined as crime. My field research shows that following the bylaw, healers continue to provide this health service depending on the patient demand. Considering that physicians must have learnt how to practice cupping therapy with all aspect of the method from traditional healers, eliminating them from practice is rather ironic. In this paper, the approaches of practitioners trained in two schools who apply cupping therapy to their patients are compiled. Main difference in their approaches is that enculturation process of first goes through in oral culture environment where master-apprentice relationship is actively followed. While folk medicine knowledge is institutionalized with in the frame of experience, religion, and folk beliefs, physicians and dentists come from the tradition in which books are main source of learning process, and based on experiment. Economic reasons, written procedures of official health services, insufficient public transportation facilities, operated language in health care, prohibitions and drawbacks related to religion and folk beliefs, gender role regulations play role in the patients' preference to resort one of these two traditions. Approaches and methods of the schools towards cupping therapy differ in the areas of procedures, hygiene, social 
contact during practice, religious and magical elements accompanying the treatment. When a patient on medication apply to healers to benefit cupping therapy, healers are reluctant to make decision about If patient should or can pursue her/his desire as this decision requires to know pharmacological lore. That is why healers direct these kind of patients to physicians to consult if their situations are suited. While healers let religious and magical elements in practice of cupping from very beginning to end, physicians display a secular attitude within the framework of ethical rules they are strictly bound to. Furthermore, healers take narratives formed around folk beliefs into their consideration while conducting cupping method. Therefore they refuse to practice in particular days and use particular things in treatment such as vinegar. Schools establish a link between healing, cure and current spiritual condition of patients as well. Whereas healers put forward that amount of the blood taken out of body in cupping process is directly proportionate to healing speed, physicians refuse this correlation grounding on experimental data.

\section{Giriş}

Folklorun bugüne kadar çok tanımı yapıldı. Bunlardan birinde folklor, "bir grup insanın ait oldukları alt kültürlerden üst kültürle çevrelenmiş yeni yaşam alanlarına taşıdıkları, alışkanlıklarındaki gibi içgüdüsel bir motivasyonla uygulamaya, yaşatmaya devam ettiği gelenekler, süreçler, dünya görüşüdür” (Tylor, 1891a: 16). Bu, grupların kendilerini grup olarak tanımlamalarını mümkün kılan kültür elementlerinin kendi doğal habitatlarında olduğu gibi sıkı takibine (Tylor, 1891b: 539) olanak tanır. Bu bağlamda folklor, grupların şehir hayatı içinde yaşatmaya devam ettiği kültür elementleri, arkaik düşünce, inanış, uygulamaların mevcut yaşam koşullarına uyarlanmış halidir.

Folklorcu için, şehirde folklorun peşine düşmek, kaydetmesi ve derlemesi kolay olmayacak yapıca ufak tefek değişikliklerle işlevini karşılamaya devam eden yeni kültür formlarının kayıt altına alınması, sınıflandırılması, arşivlenmesidir. Bunların her biri, gelecekteki nesiller için arkaik uygulamalar olacak, yeni nesillerin bunları tatbik ettiği güncel haliyle bizimkiler arasında yapısal, işlevsel farklar olacaktır. "Zamanın bir noktasında derlenip kaydedilen folklor, kültürel hafızanın bir bileşenine dönüşürken; gelecek nesiller için aynı yapı olarak yaşatılmayacaktır" (Dorson, 1970: 208). Folklor, bir ülke veya belirli bir bölge halkına ilişkin maddi ve manevi alandaki kültür ürünlerini konu edinen, bunları kendine özgü yöntemlerle derleyen, sınıflandıran, çözümleyen, yorumlayan ve son aşamada da bir birleşime vardırmayı amaçlayan (Örnek, 2000: 15) disiplindir. Bu disiplin çerçevesinde halk "en az bir ortak unsuru paylaşan iki kişinin bir araya gelmesiyle oluşan grup”tur. (Dundes, 1965: 2-3). Folklorun çalışma kadroları arasında halk hekimliği de hastalık, sağalma ve sağaltma alanında oluşan, gelişen, nakledilen sağlık bilgisidir. Modern tıbbın bu alanda uygulanagelen yöntemleri, ilaçları, inançları ve pratikleri "geleneksel tıp" (GT) şeklinde adlandırmasının altında yatan gerçeklik de söz konusu bilginin oluşumunun, gelişiminin ve naklinin sözlü ve/veya model alma yoluyla gerçekleşmesindendir. 


\section{Halk Hekimliği alanında kavramlar kargaşası: Geleneksel mi tamamlayıcı mı al- ternatif mi?}

Dünya Sağlık Örgütü'ne/DSÖ [World Health Organization/WHO] göre GT, “fiziksel ve ruhsal hastalıklardan korunma, bunlara tanı koyma, iyileştirme veya tedavi etmede, sağlığın sürdürülebilirliğinde kullanılan, kültürlere özgü inanç, tecrübelere ve teorilere dayanan, izahı mümkün olan veya olmayan bilgi, beceri, uygulamalar bütünüdür” (WHO 2000). Buna karşılık tamamlayıcı veya alternatif tıp, bir ülkenin resmi veya GT uygulamaları arasında yer almayan, kültürleşme süreçlerinin sonucu olarak bir kültüründen başka bir kültüre ödünçlenmiş sağlık uygulamalarıdır ${ }^{1}$.

GT, modern tıbbın deneysel bilgisiyle doğrulanmış halk hekimliği bilgisidir. Bu nedenle halk hekimliği alanında oluşan, gelişen tüm sağlık uygulamalarını kapsamaz. Halk hekimliği "halkın olanakları bulunmadığı için ya da başka sebeplerle doktora gidemeyince veya gitmek istemeyince, hastalıkların tanılama ve sağaltma amacı ile başvurduğu yöntem ve işlemlerin tümüdür (Boratav, 2013: 139). Sözlü etkileşim kaçınılmaz bir şekilde "doğrudan, aynı değerleri ve dünya görüşünü paylaşan, aynı vasıtaları kullanarak bağlamı yorumlayan, sonuçta aynı anlamsal sonuçlara ulaşan grup üyelerinin" (O’Connor ve Hufford, 2001: 15) dâhil olduğu bir iletişim sürecidir. Halk hekimliğinde, halkın nesiller boyu deneyimleyerek faydasını tespit ettiği sağlık bilgisi informel öğretim alanında, nesillere sözlü kültür aktarımıyla nakledilir. Uygulamalar ve teknikler arasındaki görelilik ve yerellik sözlü kültür ortamıyla doğrudan ilişkilidir. Amacı, "kullandığı maddi ve manevi araçlar yardımıyla, halkın sağlığını korumak ve hasta kimseleri sağlıklarına kavuşturmaktır” (Acıpayamlı, 1989: 5). Hastalık ve sağalma özü itibariyle grubun sürekliliğini etkiler. Terime halk hekimliğinin dünü ve bugünü üzerinden yaklaşılanlar da vardır:

Folklorcular geçmişte modern tıbbın sağaltma alanındaki boşluklarını doldurur, sözlü olarak nakledilen, ama modern tıp tarafından görmezden gelinen uygulamalara yoğunlaşırdı. Şimdi doğrudan modern tıbba ve halk hekimliğine dair tartışmalar üretmektedir (Briggs, 2012: 321).

Halk bilgisi ve bilimsel bilgi arasındaki sınırlar deney [experiment], deneyim [experience] ve bilginin aktarımı üzerinden görünürlük kazanır. Halk bilgisinin önemli bir bölümü kültürel bellekte; diğerinin bilgisi yazılı kültür ortamında muhafaza edilir, bu ortamlara has iletişim araçları üzerinden nakledilir: Söz ve yazı.

Halk hekimliği alanında hastalığın kendisi kadar sağaltmayla ilgili uygulamalar da halka açıktır. Bu bağlamda halkın anlayacağı dilde, uzmanlığına güvenilen kişilerce icra edilirken; resmi sağlık sistemi içinde bilgi kendine has bir dil, teknikle öğrenilir, aktarılır, icra edilir. Bu bağlamda resmi sağlık sistemi içinde, gayri resmi olarak tanımlanan sağaltma yöntemleri halk hekimliği çatısı altında ele alınır. "Sistemler arası farklılık, ilkinin deneyim ve inançlar; diğerinin deneysel bilgi zemininde kurumsallaşmasıdır. İkisi de neden-sonuç ilişkisi çerçevesinde teorisini geliştirmiştir" (Türkdoğan, 1974: 41).

Bilginin aktarımı, iki sağlık sistemi arasındaki farkı tasvir etmek için kullanır. "Halk hekimliği alanında uzmanlaşma sözlü aktarımla, öğrenme usta çırak ilişkisine dayalı gözlemledir. Modern tıpta matbu metinlerin okunmasıyladır" (O’Connor ve Hufford, 2001: 16). İlaveten, uluslararası alanda resmi sağlık sistemleri bir noktaya kadar halk hekimliği uygula- 
malarını destekler. Nitekim, şifacılar, resmi sağlık sisteminin yükü azaltır. Toplumun sağlık hizmetlerinden şu veya bu şekilde yararlanması noktasında alternatif merkezlerdir. "Sağaltma uygulamaları refah seviyesi, stres ve kaygıyı azaltma gibi grubun sürekliliğini sağlayan toplumsal kontrol mekanizmalarına dair datalar sunar" (Press, 1978: 71).

$\mathrm{Bu}$ nedenle, araştırma sahasında yerel halk hekimliği bilgisini derlenmek için önce resmi otoritelerin tanımladığı sağlık sistemi belirlenmelidir. Ardından, bu sistemin dışındaki aktörlerin uyguladığı yerel sağaltma teknikleri üzerinden sahanın halk hekimliği kaydedilir. $\mathrm{Bu}$ minvalde "bugün halk hekimliği içinde yer alan sağaltma bilgisinin ve tekniklerinin bir bölümü, zamanın bir noktasında tıp ilminde geçerliyken; modern zamanlarda ıskartaya çıkarılmıştır" (Yoder, 1972: 191). Halk hekimliği alanında bireyin fizikî, ruhî ve sosyal iyilik halini korumaya, iyileştirmeye ve sürekliliğini tesis etmeye yönelik bilgi akışı aralıksızdır. "Halk hekimliğinde sağlık sistemi toplumun tüm katmanlarına açıktır. Sadece bireyin değil toplumun ekonomi, din, aile, ritüel, ahlak gibi diğer kurumsal alanlarına da faydalı hekimlik bilgisi prosedürlere takılmadan uygulanır” (Manning ve Fabrega, 1973: 290). Halk hekimliğine dayalı sağlık sistemini, resmi sağlık sisteminden ayıran özellikler şunlardır:

Halk hekimliğinde hekimlik, usta çırak ilişkisine dayalı sözlü öğretimle kazanılır, aktarılır. Sağlık bireyin bedeni, ruhu ve aklı arasındaki ahenktir. Hastalığın tedavisine büyüsel, doğaüstü elementler eşlik eder. Bireyin düşünceleri, duyguları hastalıkların etiyolojisi arasındadır, bunların teşhisi tedavide rol oynar (O'Connor ve Hufford, 2001: 18).

Süreçler (doğum, sünnet vb.), hastalıklar, uygulamalar alanında uzmanlaşma vardır. "Kimi şifacılar genel hastalıklara bakarken; diğerleri hususi hastalıklarla ilgilenir: Ebeler, masajcılar, sınıkcılar, çocuk şifacıları, yanıkcılar vb." (O’Connor ve Hufford, 2001: 27; Brady, 2002: 76). Yılancık, dolama, gece yanığı (zona), çıban, aydaş, mayasıl, dalak, fitık, göbek düşüğü, karabulak, kanser, kırık-çıkık, sarılık, siğil, kadın hastalıkları, hacamat ve sülük, alazlama/ütüleme, göz/itdirseği, yarımca (başağrısı), erikleme, eşleme, işleği, gelincik, kulunç, köstü (köstebek), felç, sıtma, temre, kuduz (Üçer, 1989), mide, kulak, yel, baş ağrısı, bademcik, kabakulak, kasık silkin, korku, nazar, göbek düşme, kireçlenme, nasır, saçkıran, kabızlık, kansızlık, kısırlık, ishal, idrar, bulantı, mantar ocakları Türk halk hekimliğinde tedavide kullanılan teknikte veya hastalıklar alanındaki uzmanlaşmaya örnektir.

\section{Metodoloji}

DSÖ’nün üye ülkelerini, GT uygulamalarını ulusal sağlık sistemine bütünleştirmeye çağıdığı Pekin Deklarasyonu’yla kanıta dayalı GT bilgisinin kayıt altına alınması dünyada hız kazandı (WHO 2008). Türkiye de DSÖ’nün önerdiği geleneksel ve tamamlayıcı tıp (GTAT) adlandırmasını kabul etti. Sağlık sistemiyle bütünleştirerek konuyla ilgili yönetmeliği yayımladı. GETAT alanında geçmişten bugüne ulaşan halk hekimliği uygulamalarının bir kısmının² uygulama yetkisi hekimlere, diş hekimlerine ve bunların gözetiminde uygulanması koşuluyla temel sağlık eğitimi almış sağlık mensuplarına verildi. ${ }^{3}$ Böylece şifacıların bu yöntemleri uygulaması "Tababet ve Şuabatı Sanatlarının Tarzı İcrasına Dair Kanun” uyarınca ${ }^{4}$ suç kapsamına girdi. Uygulama alanında faaliyet gösteren şifacılar da cezalandırıldı ${ }^{5}$. 
Ne var ki 19.10.2019-02.06.2020 arasında Ankara'da yaptığımız alan araştırması, Akyurt, Etimesgut, Sincan, Çubuk, Pursaklar, Yenimahalle semtlerinde haccamlıkla/hacamatcılıkla geçinen şifacıların faaliyetlerini sürdürdügüunü, konuyla ilgili tanınma, onaylanma girişimlerinde bulunduklarını gösterdi. Şifacılar, onaylanmak için özel kurslara katılıyor, ustalıklarını onay mercilerine sunuyordu. Bu belgeler hastaların kabul edildiği odanın duvarına asılıyor, şifacı marifetini belgeleyerek bir yere kadar kendisini koruyordu.

Hacamat yapan şifacılara haccam Y. Çılgı vasıtasıyla ulaşılmıştır. Kılavuz kaynak kişi aracılığıyla ulaştı̆̆ımız, yaşları 26 ile 63 arasında değişen kadın ve erkek on dokuz şifacıdan on biri bu tür belgelere sahiptir. Diğerleri belgeleri olmadığg gerekçesiyle görüşme talebimizi reddetmiştir. Sertifikalılardan yedisi çalışmamıza gönüllü kaynak kişi olarak katılmayı kabul etmiştir.

Sertifikalı hekimlere kılavuz kaynak kişi Hekim M. Kara (2020) vasıtasıyla ulaşılmıştır. Hekimler özel kliniklerde bağımsız çalışan, Sağlık Bakanlığı onaylı sertifikaya sahip ve Ankara'da hacamat/kupa terapisi yapanlar arasından seçilmiştir. Sertifikalı uzman hekimlerin, uzmanlık alanları dahiliye, iş yeri hekimliği, spor hekimliği, ortopedi ve travmatoloji, cildiye, beyin cerrahisi, anestezi, nörolojidir.

Hastalara, hekimlerin ve şifacıların hacamat günlerinde hazır bulunularak ulaşılmıştır. Hekime ve/veya şifacıya en az üç seans giden hastalardan gönüllüler araştırmaya dâhil edilmiştir. Böylece araştırmada sağaltan ve sağaltılan arasındaki ilişkiye, hastanın hastalığına ve sağaltma tekniğine dair bilgisine, deneyimine dair halk bilgisi derlenebilmiştir.

Şifacılar, hekimler ve hastalarıyla derleme yaparken yönlendirilmemiş görüşme tekniği kullanılmıştır. Bu yöntem kaynak kişinin bir konuda neredeyse tamamen serbest ve genel mahiyette konuşmasını, araştırmacıya "kaynak kişiyi hazırlıksız ve ayrıntılı cevaplar vermeye teşvikle, çeşitli konularda geniş bilgi” (Goldstein, 1983: 75) sağlar. Böylece kaynak kişinin konu hakkındaki görüşleri, değer yargıları ve duyguları da kaydedilir. 19.10.201916.12.2019 arasında şifacılarla mülakatlar yüz yüze iletişim ortamında, hastalarını kabul ettikleri mekanlarda; hekimlerle 04.01.2020-02.06.2020 aralığında yüz yüze iletişim ortamı canlı veya online programlar üzerinden tesis edilmiştir.

İnternet, folklor araştırmalarında uluslararası projelerin hayata geçirilmesini mümkün kılmakla kalmayıp, derlenen halk bilgisinin de otomatik, daimi şekilde kaydedilmesini sağlar. Bir avantajı da "derleme kaydının ham haliyle dünyanın tüm folklorcularının erişimine açılabilmesidir" (Kirshenblatt-Gimblett, 1996: 44). Nitekim folklorun belirli bir alanına yönelik derlenen ham bilgi, diğer alanlara dair halk bilgisini de içerebilmektedir. Derleme kayıtlarında halk hekimliği alanında bilgi kaydetmek amaçlanmış, görüşmelerin içeriğinde sağlık politikaları, sağlık sisteminde bürokrasi, hekim folkloru, göreli estetik, halk ekonomisi alanlarında da bilgi kaydedilmiştir. İnternet, araştırma konusuyla ilgili soru ve sorunların tespit edilmesinden, materyalin derlenmesine, sınıflandırılmasına ve arşivlenmesine kadar tüm süreçlerde folklorcu için ihmal edilmemesi gereken bir alandır.

R. Bendix'in (1998: 243) söylediği gibi alan araştırması uzaklıklarla sınırlandırılamaz Online alan araştırması aynı zamanda birden çok mecrada derleme yapabilmeye olanak sağlar. Kaynak kişinin araştırmacıya sağladığı bilginin güvenilirliğine gelince; bu canlı yüz yüze alan 
araştırmasında da araştırmacının kaygıları arasında hep yer almıştır. "Online derlenmiş halk bilgisi, en az canlı yüz yüze iletişim ortamında derlenen kadar otantiktir” (Blank, 2007: 21). Üstelik "kaynak kişilerin sözlerinin doğruluğunu ölçmek, yargılamak için ekstra kriterler belirlemek araştırmacının işi değildir" (Hine, 2000, 49). Online derleme yapılırken de, "materyalin anonimliği, kaynak kişinin güven ortamından emin olmak, kaynak kişilerden onay alınması ve mahremiyete hürmet” (Carter, 2005: 152) araştırmacının manevi sorumluluklarıdır.

Şifacıların, hacamatı tedavi yöntemi olarak uygulaması suç olarak tanımlandığından kaynak kişilerin gerçek adları örtülmüştür. Sosyal bilimlerin bir çok disiplininde geçerli etik kuralları doğrultusunda kaynak kişilerin aile ve sosyal hayatlarındaki güvenliklerini garanti altına almak için bu yol tercih edilmiştir. Kaynak kişilerin cinsel içerikli, dinî, etnik ve hukukî vb. konularda bilgi sağlamaları halinde araştırmacının etik sorumluluğu kaynak kişinin araştırmanın yayınlanmasından sonra güvenliğinden emin olmaktır. Bu tür durumlarda kaynak kişilerin isimleri yerine ardışık sayıların, harflerin (001, 003; KK1, KK2 ...), kullanılması başvurulan bir yöntemdir. Bu yöntemler kaynak kişilerin insan dışı varlıklarmış gibi konuşturulması yönüyle tercih edilmemiştir. Bu kodlar, kaynak kişinin, gerçekte bir insan olduğunun unutulmasına neden olur. Bir zaman sonra kaynak kişi insan dışı bir varlığı, metin içinde konuşturuyormuşçasına soyutlaşır. Araştırmanın yayımlanmasının üzerinden geçen zaman paralelinde araştırmacı ve kaynak kişi arasındaki bağı zedeler. Kaynak kişinin kod içine gizlenmiş gerçek adı, zamanla unutulur, bilgisi soyutlaşır. Bu nedenle folklor, sosyoloji, antropoloji gibi alan araştırmasından beslenen disiplinlerde kaynak kişiye verilen müstear adın, kaynak kişinin gerçek adını çağrıştıran nitelikte olması tavsiye edilir (Murchison, 2010: 204; Hicks, 1977, 216; Guenther, 2009: 414). Bu araştırmada da kaynak kişilerin ilk isimleri baş harf göstererek; soyadları ise gerçek soyadını çağrıştıracak müstear adlarla değiştirilerek örtülmüştür.

Savaşlar, afetler, salgınlar gibi toplumsal vakalar araştırmacının kaynak kişiye ve araştırmaya karşı sorumlulukları arasına bir yenisini daha eklemiştir: Kendisinin ve kaynak kişinin fiziksel, ruhsal, zihinsel sağlı̆̆ını koruyan tedbirler almak. Böyle bir ortamda internet hem araştırmacının hem de kaynak kişinin lehine bir derleme ortamı olarak işlevseldir. COVID 19 salgını sürecinde gerçekleştirilen online derleme kayıtlarında sözlü izin WAV ses dosyasına kaydedilirken, imzalı etik izin formları e-posta vasıtasıyla alınmıştır. Formları tarafımıza ulaştır[a]mayan kaynak kişilerden derlenen halk bilgisine metin içinde yer verilmemiştir.

\section{Halk hekimliğinden GETAT'a: "Kırk yıllık hacamat oldu kupa terapisi!"}

Hacamat, Arapça'da hicâmet şeklinde kullanılıyor olup, anlamı "boynuz veya şişeyle kanı topladıktan sonra neşter, mengene denilen aletlerle kan alma” (Devellioğlu, 2006: 305) işlemidir. Hacamat yaptırmaya ihticâm; meslek erbabına haccâm; uygulamada kullanılan aletlere mihcem denir (Köşe, 1996: 422). Kanı, vücudun bir bölümüne toplamak için yapılıyorsa kuru hacamat (dry cupping); vücuttaki kanı dışarı akıtmak için yapılıyorsa kanlı hacamat (wet cupping) adını alır. Kuru hacamata halk arasında "şişe çekmek" denir.

Antik tıpta "hastalığa neden olan, olması muhtemel toksik veya zararlı kanın hastalığı önleme veya iyileştirme amacıyla alınması” (Qureshi ve ark., 2017: 174) anlamında kullanıldığını 
bilmekteyiz. Hacamat, Eski Mısır, Çin ve Yunan tıbbından dünyaya yayılmıştır. Baş ağrısı, iştahsızlık, sindirim hastalıklarının tedavisinde kullanılmıştır. Hipokrat da kanlı hacamatı bir tedavi yöntemi olarak (Turk ve Allen, 1983: 128; Qureshi ve ark., 2017: 174) kullanmıştır.

İslâm medeniyet dairesi tıp bilgisinde, hacamatın ilgili hadis ve sünnetlerden ${ }^{6}$ hareketle tatbik edildiği görülür. Bu sahada verilen yazılı eserlerde tıp bilginleri, hacamatta hadise ve sünnete paralel bir uygulama usulü geliştirmiştir. Bu minvalde İbn-i Sina da hadis ve sünnete atıfta bulunarak hacamatta orta yolun icrasını önerir. Hacamatı, deri üzerine açılan çizgiler, kesiler üzerinden kirli kanı dışarı akıtmak şeklinde tarif eder. Eflatun'un da kafasının üst kısmından kal aldırdığını naklettiğinden bahseder (Tokadî Mustafa Efendi, 2018: 956).

Seyyahlar, hacamatı kan alma işlemi şeklinde tanıtır. Thevenot, Türklerin başları ağrıdığında neşterle kesip, epey kan aldıktan sonra yarayı pamukla kapattıklarını, işlem sırasında alına beş, altı çentik atıldığını söyler. Bu işlemin çoklukla dönmeler(mühtedîler) tarafından yapıldığını, bazı Türklerin de bu işte mahir olduğunu, ama neşterle uygulamayı yaptıklarını haber verir (2014: 75-76). Evliya Çelebi, hacamatın kadın dellâklarca ${ }^{7}$ yapıldığını kaydeder $(2011,101)$. Osmanlı halkı arasında hacamatın bir sağlık kuralı olduğunu, bunda Ermeni berberlerin mahir olduğunu, dana boynuzundan kupalar kullanıldığını, kuru ve kanlı hacamatın birlikte yapıldığını (Abdülaziz Bey, 1995: 350) bilinmektedir.

Hacamat, geleneksel zeminde çıraklara model alma, gözlem yoluyla öğretilir. Uygulama, hastalık ve sağaltmaya dair halk bilgisi de ustadan çırağa sözle nakledilir. Çırağın kendi başına yaptığı ilk hacamat uygulaması ritüele dönüşür. Ustaya erişimin kolaylığı bakımından çırakların, ustanın akrabaları arasından seçildiği ve yetiştirildiği görülür. A. Köksal'ın bu husustaki ifadeleri şöyledir:

$\mathrm{Bu}$ bir sanattır, altın bileziktir. O yüzden yanımda yetişenin kız olmasını tercih ederim. Okula gitsin, gitmesin, bir sanatı olsun ki, başına bir hâl gelse, bu işten ekmek yesin. Gördüğünü unutmamalı, titiz olmalı. Kupayı ne için nereye vuracağını aklında tutmalı. Bir de kan tutmamalı. Streslisin, yeri gelir azarlarsın. Çırağın el olursa bir iki azarlasan üçüncüye gelmez. O yüzden kendi canın, kanından olsa nazını çeker. Ben halamdan öğrendim (Köksal, 2019).

Hacamat tekniğinde ustalaşmış şifacılar, çıraklarını çoğunlukla hemcinslerinden seçmekte, karşı cinsten çıraklarla aralarında akrabalık bağı olmasına dikkat etmektedir. Çırağın kendi başına yaptığı ilk başarılı hacamat uygulamasını takiben, çırağa hacamat seti almak ustalar arasında geleneğe dönüşmüştür. Usta şifacılar, çıraklarını seçerken el yatkınlığı, hafıza gücü, merak duygusu gibi özelliklere odaklanmaktadır.

Modern tıbbın GETAT alanında, hacamata kupa terapisi (cupping thearapy) denilmektedir. Beş sınıfa ayrılmaktadır. Bunlar "kuru kupa, ıslak/kanlı kupa, flash/boş kupa ve masaj kupa terapisi”( Parlakpınar ve Polat, 2020: 248) şeklindedir. Bu sınıflandırma içinde araştırmamıza konu olan hacamat, 1slak kupa terapisine karşılık gelmektedir. Hacamat, "bölgesel vakum aletleri yardımıyla, vücuttaki enerjiyi bloke eden çoğunluğu kapiller damarlara ait toksik maddelerin teşkil ettiği kanın, yüzeysel cilt kesikleri oluşturarak emniyetli bir biçimde alınmasını sağlayan işlemdir” (Sert, Sakarya, Yüksel, Sert ve Kalayc1, 2015: 19-25). Deney- 
sel çalışmalara göre (Okumuş, 2016: 375-379), hacamat ödeme sebep olan maddeleri, toksinleri, bakterileri, zararlı kimyasal ve biyolojik maddeleri; ağır metalleri, ilaç kalıntılarını, kimyasal ve endojen maddeleri; yanık ve intihaba bağlı ödemi vücuttan atmada; hücreler arası dokunun temizlenmesinde ve basıncının azaltılmasında rol oynar. Bulgular halkın deneyimle tespit ettiği faydaların deneyle doğrulandığı yönündedir.

\section{Hasta, Hastalık ve Hacamat: "Duydum, İnandım, Buldum, İyileştim"}

Hacamata yönelen hastalar, evvelce bu tedaviye başvurup, iyileşenlerin deneyim anlatılarına kulak vererek hekime veya şifacıya gitmektedir. Bu kişisel deneyim anlatıları, hastanın haccamla veya hekimle tanıştı̆̆ 1 andan başlayıp, iyileşmeyi takip eden süreci de kapsamaktadır. Aşağıdaki anlatı bu bağlamda kayda değerdir:

2011 yılında hanımım başını duvardan duvara vururdu. Öyle bir ağrı çekerdi. Başladı mı on gün bazen bir ay onu unutun. Bir gün hastanede yine sıra beklerken, bir başka hastanın yakınıyla yan yana düştük. Burada bir doktor başı ağrıyan hastalara hacamat yapıyormuş. Bir kadın varmış, doktor hiçbir çare bulamayınca demiş ki: "Teyze sana hacamat yapayım desem ne derdin?” Kadın demiş ki, "şu an başımı kes de yeniden dik. Hissetmem oğlum. Ne yapıyorsan yap, ben ölmüşüm” demiş. Kadının daha ilk seferden başının ağrısı geçmiş. Torunlarına bakıyormuş şimdi. Ben bunu duyunca doktorun peşine düştüm. Sordum soruşturdum. "Adana'ya gitti” dediler. İnternetten hacamatcı buldum. Hanımım iyileşti, üç dört kez aralıklı gittik. Şimdi yılda bire düştü. Yine de ağrısı oluyor, bir iki gün derken ayaklanıyor (Demir, 2020).

Halk, ilaçların, yöntemlerin yayılması noktasında deneyimden elde edilen faydaya odaklanır. Birine faydası dokunan ilaca, yönteme, doktora, şifacıya dair bilgi sözlü iletişim ortamlarında yayılır. Bu da bize "Sağaltma yöntemi özellikle de hastanın bizzat tanıdığı birinin deneyimlediği bir sağalma anlatısıyla destekleniyorsa meşruluk kazanır”(Brady, 2012: 76) sözlerini hatırlatır. Son minvalde hastalıkla mücadele eden birey, bu meşru yöntemi denemeye ikna olur.

Literatüre bakıldığında halkın neden şifacılara yöneldiğiyle ilgili teorilerin çeşitlendiği görülür (Acıpayamlı, 1969, Artun, 2005, Boratav, 2013). Modern ve kurumsallaşmış tıp hizmetine erişimi olan toplumlarda hastanın, hastalıktan sağalmak için önce hekimlere sonra şifacılara gitmesi söz konusudur (Yoder, 1972: 192). Öyle ki orta sınıfa ve işçi sınıfına mensup kişiler, sınıflarının sunduğu sağlık olanaklarını önce modern tıp alanına; sonra şifacılara başvurmak şeklinde tercihen kullanır. "Hastaların modern tıpla sağaltılamayan hastalıklar için şifacılara yöneldiği” (Sever, 2015: 196) de kaydedilmiştir. Ekonomik sebepler, resmi sağlık hizmetlerinin yazılı prosedürleri, ulaşım olanaklarının yetersizliği, modern tıp dili ve halk dili farkı, din ve inançlar dairesindeki yasaklama ve çekinceler, toplumsal cinsiyet rollerine bağlı düzenlemeler hastanın hastalık halinde resmi sağlık hizmetlerine başvurmayı tercih etmemesi veya geciktirmesinin nedenleri arasındadır. 


\section{Hekimler ve şifacılar elinde hacamat: Hastalıklar,yaklaşımlar, uygulamalar}

Araştırmamız, Ankara'da hacamatla sağaltmaya başvuranların migren, bel fitığı, fibromiyalji, depresyon, yüksek kolesterol, Tip 1 ve 2 diyabet, kas ağrıları, dolaşım hastalıklarından mustarip olduğu; bu hastalıklarla ilgili uzmanlaşmış hekimlere başvurarak ilaç tedavisi gördüğünü, tedaviden olumlu sonuç alamayanların hacamata yöneldiği göstermiştir.

Uzun yıllardır baş ağrısı çekiyordum. Kas ve eklem ağrılarım da vardı. Tomografi, MR çekildi. İlaçlar kullandım. Patolojik bir nedeni olmadığı anlaşıldı. Bir yakınım aracılığıyla bir doktorun hacamat yaptığını, iyileştirdiğini duymuştum. Bunu birkaç kişiden duyunca inancım çoğaldı. Gitmeye karar verdim. Raporlarımı, tahlillerimi de götürdüm. Fiziki muayenemi yapınca, önce osteopati yaptı. Sonra hacamatla iyileşebileceğimi söyledi. Ben de "hocam beni bu ağrıdan kurtarın da ne yaparsanız yapın" dedim. Diyetimi verdi, bir hafta sonra hacamata gittim (Veren, 2020).

İlaçlı tedavi görürken geleneksel tedaviye yönelme süreci kaynak kişi tarafından şu sözlerle anlatılmıştır:

Bir iki yıl kadar o ilaçtan başka bir ilaca ne varsa denedim. Benim doktorum, benim durumumdaki kimi hastalarda hacamat tedavisiyle düzelmelerin olduğunu söyledi. Doktorum dört seans hacamat yaptı. İlk seferinde başımdan kan çekilirken tüm ağrının, acının da çekildiğini, bedenimi terk ettiğini hissettim. Sanki başımın içinde bir kütle varmış, başımın içinde oturuyormuş da beynimi ele geçirmiş, kanla beraber dışarı çıkıyormuş gibiydi. Bir buçuk, iki yıl sonra ilk kez o gece deliksiz, huzurlu bir uyku uyudum. İşe yarayacağını o gün anladım (Gültepe, 2019).

Hekimler ilaç tedavisinin kesilmesinden birkaç hafta sonra hacamat yapmaktadır. İlaçtan somut fayda göremeyen hastalara hacamat öncesinde arındırma diyetleri vermekte, bu süreçte hastanın günlük tükettiği su miktarını da 500 ml. ile $1000 \mathrm{ml}$. arasında arttırmaktadır.

Geleneksel şifacılarsa ilaç tedavisini kesip kesmemek noktasında karar yetkisini hastaya bırakmaktadır. Kararın bir doktora danışarak verilmesinden yanadır. Bu yaklaşımda farmakoloji formasyonundaki yetkinliğin rol oynadığı görüldü. Şifacı A. Köksal'ın bu konuda sözleri şöyledir:

Biz doktor veya hemşire değiliz. Böyle bir kararı alamayız. Hasta bu konuda kararı doktoruna danışarak vermelidir. Ben hacamatın hangi hastalıklarda, bedenin hangi bölgelerine yapılacağını bilirim. Üç gün diyeti biz de veriyoruz. Suyu fazla tüketmesini biz de istiyoruz. Diyet yapmamış bir hastaya hacamatı zaten yapmayız. Yine de hastanın bize söylediği esastır. Aç karnına, üç gün hayvanî bir gıdayı yememiş, içmemiş olarak bize gelmesi gerektiği kendisine söylenir (Köksal, 2019).

Ankara'da işlettiği aktariyenin bir bölümünü geleneksel bir kliniğe dönüştüren Y. Çılg1, kendisine tedavi için müracaat eden hastaların şikâyetini, tedavi öyküsünü kaydederken ilaçları da not almaktadır.

Ben sadece bel, kas ağrısı, kemik ağrıları, migren ve fitık bakıyorum. Bunların dışında bize başvuranları doktora yönlendiriyorum. Adam doktora gidiyor beş altı dakika doktorun yanında ancak durabiliyor. Ne ara derdini anlatacak da akıl soracak? Eşi dostu doktor olan hastalarımız var, onlar kendileri bir şekilde danışıp, akıl soruyorlar (Çılgı1, 2019). 
Sincan'da hacamatcılıkla geçinen S. Soylu (2019) ve K. Soylu (2019) da bu hususta meslektaşlarıyla aynı görüştedir. Hastası N. Öz (2019) ilaçlarına devam ederken hacamat olduğunu şu sözlerle anlatmaktadır:

Çocukluğumdan beri migren hastasıyım. Eskiden yılda bir iki gelen ataklar, son zamanlarda ayda bire kadar sıklaşmıştı. Bir arkadaşımdan Ankara' da bir bayanın migreni hacamatla iyileştirdiğini duydum. S. Hanım'a ulaştım. Telefonda bana et, süt cinsinden hiçbir şeyi üç gün süreyle yememem, kullandığım bir ilaç varsa doktorumdan izin almam gerektiğini söyledi. Ben de bizim işyerinin hekimine sordum, “sıkıntı olmaz. İşe yaramasa da zararı da olmaz” dedi. Öyle başladım (Öz, 2019).

İlaçların hastalıklar üzerindeki yapısal ve işlevsel etkisinin kapsamlı bir bilgi alanı olması, şifacıların bu alandaki karar yetkisini hekimlere bırakmasının gerekçesi olarak kaydedilmiştir.

\section{Hijyen prosedürleri}

Şifacıların ve hekimlerin hacamatta takip ettikleri hijyen prosedürleri ve sosyal temas yaklaşımlarında farklar kaydedildi. Ankara'da hacamat yapan şifacıların aktariyeler içinde düzenledikleri klinikte, evde müstakil bir odada, evin salon veya oturma odasında hasta kabul ettiği görüldü. Bu ortamlarda şifacılar, tek kullanımlık tek kullanımlık eldivenle; halı, yemek masası veya muayene masasında; piknik örtüleri, şifacı veya hasta tarafından tedarik edilen çarşaf, naylon örtüler üzerinde, yatış veya oturma pozisyonunda hacamat uygulamaktadır.

Hacamatın baş bölgesine yapılması halinde uygulamanın yapılacağı alanın ustura vb. aletlerle tıraş edildiği; sirke ile temizlendiği; tek kullanımlık jiletle kesilerin açıldığı ve işlemi takiben yine sirke ile yaranın temizlendiği görüldü. İşlem sırasında kullanılan kupalar tek kullanımlık; pompa ise çok kullanımlıdır. Malzemeler şifacılarca tedarik edilmektedir. Akyurt'ta mülakat yaptığımız N. Usta (2019), hacamatta yara temizliğinin sirke ile yapılması hususunda şu bilgileri vermektedir:

$\mathrm{Bu}$ işin geleneğinde kesilecek yer hacamattan önce ve sonra sirke ile temizlenir. Yanıkta, sivilcede, çıbanda intihap olmasın diye de sirke kullanılır. Bizim hocalarımız, mesleği öğrendiğimiz işin erbabı kişiler böyle öğrettiği için biz de böyle yapıyoruz. Bir de sirke büyü ve nazar üzerinde tesirlidir.

Hekimlerin muayene ortamında tek kullanımlık muayene masası ve örtüsü üzerinde; tek kullanımlık eldivenle hacamat yaptığı görüldü. Hastanın kesilerinin açılmasında neşter kullanılmaktadır. Hasta kupa setini (kupa, neşter, pompa) kendisi tedarik etmektedir. Bu yaklaşımın gerekçesi hekimlerce şöyle açıklanmaktadır:

İşlem seti ucuz, eczanelerde var. Maksadımız hastanın bizim bundan bir kazancımız olduğunu düşünmesine sebep olacak bir duruma kendimizi düşürmemek. Biz alıp, hastadan parasını istesek, hasta bizim bu işten bir kârımız olduğunu düşünebilir. Hastanın gönlü rahat, her şey tek kullanımlık, açıyoruz, kullanıyoruz. Gözünün önünde tıbbi atık kutusuna atıyoruz (Tos, 2020).

Hacamat sırasında 1-1,5 mm. derinliğinde kesiler açıyoruz. Bu kesilerin yüzeysel olması önemli, hacamatın amacı dolaşıma girmeyen kanı dışarıya çıkarmak. Kesiler derin açılırsa dolaşıma giren kan yüzeye çıkar. Doğru yapılan hacamat sonrası 
yara dokusu oluşmaması beklenir, işlemi takip eden birkaç gün içinde yara iyileşir, yaranın üzerinde yüzeysel kabuklar oluşur, kaybolur. Biz batikonu temizlik için tercih ediyoruz, sirke de aynı işi görür ama açık yaraya sirkenin doğrudan sürülmesi hastanın canını yakar, skar doku oluşumunu tetikler. Antiseptikler yaranın enfeksiyon kapma riskini minimalize eder. Hasta isterse, altı yedi saat sonra duş alabilir, ama en doğrusu yirmi dört saat beklemektir. Yarayı sudan ve soğuktan korumak skar doku oluşumunu engeller (Tik, 2020).

Hekimler, kesilerin açılacağı alanı işlem öncesi ve sonrası antiseptik çözeltilerle temizlemektedir. Temizlenen hacamat yarası, tek kullanımlık steril kompresle kapatılıp, bantla sabitlenmektedir. Hastaya, yarasının yirmi dört saat soğuktan ve sudan korunması gerektiği söylenmektedir.

\section{Dinsel ve büyüsel elementler: Kutsal ve seküler arasında şifa}

Gözlemlemediğimiz uygulamalar özelinde şifacılar, uygulama başlamadan önce hastaya, dinlemesi veya sesli okuması gereken dua ve sureleri tarif etmektedir. Kimi hastaların söz konusu dua ve sureleri ezberden bilmediği durumlarda şifacılar bunları hastalara akıllı telefon marifetiyle dinletmektedir. Böylece doğası itibariyle karmaşık olan şifanın hastaya erişmesi için doğa üstü alanla işbirliğine gidilmektedir.

Uygulamaya başlarken bayan şifacılar "el benim elim değil Fatma anamın eli” diyor, ardından besmele ve "Ya Şâfi" diyerek işleme başlamıştır. Şifacılar akıl ve ruhla ilgili hastalıkları, doğrudan doğa üstü alanla ilişkilendirmekte; hastayı hacamat yaparken dua ve sureleri okumakta, dinlemektedir; kendisini, hastasını, hastalığa neden olan doğa üstü varlıklardan korumaktadır.

Şifacılar, Çarşamba, Cumartesi günü ve ayın çift günlerinde hacamat yapmamaktadır. Bunun iki izahı vardır. İlki Çarşamba günleri hastalıkların çoğaldığı, mevcut hastaların iyilik hallerinin kötüye döneceğine dair halk inancıdır. Kaynak kişi B. Sel (2019) bu hususta şunları söylemektedir: Çarşamba yeryüzüne hastalıklar yağar, yeryüzünden olanlardan çok, hiç bilinmeyen devasız hastalıklar yağar. O gün bedenlerde yara açılmaz. Sünnet, tıraş, tırnak kesmek hele de hacamat hiç yapılmaz. Yara açılınca yeryüzüne düşen hastalıklar gelir o yaranın üzerine yapışır.

Pursaklar da görüştüğümüz kaynak kişi de "Çarşamba günü açılan yaraların içine cinler yuva yapar. O yüzden hacamat yapılmaz, sünnet olunmaz.” (Mutlu, 2019) şeklinde yorum yapmaktadır. Çarşamba ve Cumartesi günleriyle ilgili bu yaklaşımın bir diğer izahı da hadislere dayanmaktadır. ${ }^{8}$ Hacamatın tatbikatıyla ilgili usullerin Türk-İslâm kültür ekolojisinde hadislerle şekillenmiş olması, geleneksel şifacıları Çarşamba ve Cumartesi günleri hacamat yapmaktan men etmektedir.

Hacamata eşlik eden dinsel ve büyüsel öğelerden biri de faldır. Kana bakarak hastalığın nedenleri üzerinde yorum yapan şifacılar Ankara'da rağbet görmektedir. Bayan hastalar bu tür şifacılara hacamat yaptırmak için evlerde günler düzenlenmektedir. Birbiriyle yakından tanışan akraba, komşu ve tanış olan hanımlar bir evde toplanarak hacamat yaptırmakta, hacamat sonrası kupada toplanan kan üzerinden yapılan yorumları dinlemektedir. 
S. Karslı (2020), hastanın kanının rengini, yoğunluğunu, pıhtılaşma hızını esas alarak hastalığa neden olan büyü, nazar, geç saatte tekinsiz yerlerde dolaşma, kırk basması vb. nedenleri tespit etmekte, bunların ortadan kalkması için içeriği dualardan oluşan reçeteler hazırlamaktadır. Diğer geleneksel şifacıların da kupa içine dolan kanın rengini, pıhtılaşma sürecini, kan üzerinde beliren köpükleri, kanın kupa içindeki dağılımını esas alarak hastalığın sebebini, içeriği ve iyileşme sürecine dair çıkarımlarda bulunmaktadır. Hastalar, kan üzerinden hastalığa ve iyileşme sürecine dair yapılan yorumları, dikkatle ve inançla dinlenmekte, dikkate almaktadır. Bu hususta B. Sel'in (2019) şu sözleri dikkate değerdir: Hacamatın kendisi kadar, çıkan kanın şeklinden şemailinden sebep yapılan yorumlara da iman ederim. Dikkatle dinlerim. Hocalık bir şeyim varsa onun da icabına bakarım. Bu sayede çok belanın eşiğinden döndüm.

Şifacı A. Köksal (2019), hacamat sonrası kupaya topladığı kanı yorumlamayı reddetmektedir. Sorulara fırsat vermemek için kupayı kesilerin üzerinden kaldırır kaldırmaz dökmektedir. Yine de hastaların kupanın fotoğrafını çektiği veya yanlarında gelen refakatçilerin kupadaki kanın görüntüsünü kaydetmektedir. Bu minvalde L. Yolcu (2019) koyu, siyaha dönük renkte kanın büyüye işaret ettiğini şu sözlerle ifade etmektedir:

Üç dört ayda bir boynumun ortasından iğne sokulur gibi bir his oluyor. Bu başlayınca kendim şu iki kaşımın arasından ince ince kan akıtasım geliyor. Bunu doktorlara anlatsam beni deli sanırlar. Ama aynen böyle oluyor. Kanla beraber nazar, büyü de çıkıyor. Kan kokuyor, kapkara oluyor. Her zaman değil, üzerimde büyü, kötü göz varsa rengi kararıyor. Zaten bu alındıktan sonra hafifliyorum (Yolcu, 2019).

Hacamatın hekimlerce uygulandığı durumlarda da hastaların yukarda zikredilen dua ve sureleri okumakta, dinlemektedir. İlgili ayetleri ezberden okuyamayan hastalarsa kulaklıkla bunları dinlemek konusunda isteklidir. Ameliyatların dini bir boyutu yok, ama çok görüyoruz hasta ameliyata hazırlanırken de dua eder, ezberden kuran okur. Bazen telefondan açar dinler. Hastaya iyi geliyor, onun kendini daha iyi hissetmesini sağlıyorsa ne zararı olacak (Kara, 2020).

Hastaların talepleri, davranışları hekimlerce anlayışla karşılanmaktadır. Bir hasta işleme besmeleyle başlamadığı için hekimini uyarmış, hekim hastasını memnun etmek için bismillah diyerek işlemi başlatmıştır. Bu uygulamada hasta, yakınlarından dinlediği sağalma konulu kişisel deneyim anlatıları doğrultusunda, iyileşeceği yönünde bütün bir inanç geliştirerek hekime başvurmuştur:

Hasta iyileşeceğine öyle inanıyordu ki! Üç beş ay sonra onu daha kötü bir halde bulmaktansa, "Bismillah" diyerek hastayı memnun etmek aklıma yattı. Benim inancımda böyle şeyler yok, ama hastaya faydası varsa, iyileşmesinde etkili olacaksa okusun, okudu da zaten. Ben "Oku!” da demem, “Okuma!” da demem. Karışmam ama anlarım. (Tos, 2020).

U. Tik (2020) “... Biz de hastayla aynı dindeniz, okudukları bize yabancı şeyler değil ki! Her şeyi bilimle açıklayamıyoruz ki, bu bir gerçek.” ifadeleriyle konuyla ilgili görüşünü paylaşmıştır. Bununla birlikte, hekimler genelde hacamatta bir gün ayrımı yapmamaktadır. Hastaların Pazartesi ve Perşembe günlerinde yoğunluk oluşturmakta, bu durumun doktorların programlarını etkilediği Hekim F. Kılıç (2020) tarafından şu sözlerle ifade edilmektedir: 
Pazartesi ve Perşembe günleri, özellikle ayın tek günlerinde günde iki, üç hasta mutlaka hacamat için geliyor. Aralarda gelenler de çoğunlukla bilgi almaya gelir. Biz de kendimizi buna göre hazırliyoruz. Onlar diyeti yapmadan gelmişlerse, kan sulandırıcı, insulin gibi sürekli kullandıkları bir ilaç varsa, geldiklerinde bilgilendirip, bir iki hafta sonrasına işlem için gün veriyoruz.

Hekimlere başvuran hastaların Çarşamba günlerine randevu almadıkları, bu hususta hasta tercihine dayalı hacamat günleri oluştuğu görülmektedir.

\section{Hacamat noktaları ve kan miktarı}

Her iki grup kendilerine hacamat için müracaat eden hastalarının kâhil noktasına hacamat yapmaktadır. Kâhil noktası kürek kemikleri arasında yer alan, kanla ilişkilendirilen hastalıkların sağaltılmasında hekimlerin ve şifacıların önemle üzerinde durdukları hacamat noktasıdır. Kahil noktasına hacamatın her hastalık ve her seansta uygulanması konusunda hekimler ve geleneksel şifacılar hemfikirdir. Diğer noktalarda ekollerin, bir seansta uygulanacak kupa sayısının belirlenmesi ve kanın miktarı açısından usul ve yaklaşımları farklıdır.

Şifacılar tek seansta sayısı 5 ile 20 arasında değişen noktadan hacamat yapmaktadır. Örneğin migren şikâyetiyle şifacıya başvuran hastanın başı tıraş edildikten sonra başa üste bir; başın alt kısmına üç kupa gelecek şeklide; boyuna iki kupa; sırt bölgesine bir kupa yapıştırılmaktadır. Bu kupaların içine eş zamanlı bir şekilde kan çekilmektedir. Kupaların içi kanla dolduktan sonra, kupalar kaldırılmaktadır. Şifacı M. Uslu kupaların içinin kanla dolmasını beklemekte; kupaya dolan kan miktarının çokluğunu iyileşme süreciyle ilişkilendirmektedir: "Kupaya ne kadar çok kan dolarsa hastanın iyileşmesi de o kadar hızlı olur, hasta kanın rengi koyu, kapkara oluyor. Kupayı yapıştırıp, kupa içindeki havayı çektikten sonra dolmasını beklerim" (Uslu, 2019).

Hekimler ise hacamat yapılacak yere kaç kupa yerleştirileceğine, hastanın seansına ve hastalığına göre karar vermektedir. Migren şikâyeti için hekime başvuran hastaya ilk seansta başın üst kısmından tek bir kupa ve kahil noktasına bir kupa ile hacamat yapılmakta, takip eden seanslarda kupa miktarı arttırılmaktadır. Hekimler kupayı yerleştirip pompayla çekilmesi sırasında üç-yedi dakika kuralını uygulamaktadır. Üç-yedi dakika kuralı hekim D. Karasu (2020) tarafından şu sözlerle anlatılmaktadır "Kupa içine gelen kan miktarının hastanın sağlığına katkısı üzerine deneysel bir bulgu görmedim. Hastanın kanayan yarasının üzerinde kupanın çok uzun süre tutulması doku hasarına neden olabilir. 3-7 dakika yeterlidir". Hekim C. Bilgin (2020) de konuyla ilgili yaklaşımını şu sözlerle aktarmaktadır:

Hastanın evvelce hiç hacamat tecrübesi yoksa, bedenin özellikle baş bölümünde tek bir kupayla müdahaleyi tercih ederim. İlk seansta beklentiyi düşük tutmak, hastayı rahatlatacak miktarda kanı alarak seansı tamamlamak yerinde, yeterli bir yaklaşımdır. Bir de hacamatla kupaya aldığımız kan dolaşımda olmayan kan, bu da maksadı itibariyle az olacaktır zaten.

Bu minvalde, şifacılar ilk seanstan itibaren kupa sayısını çok tutarken hasta memnuniyetini de göz önünde bulundurmaktadır. Hasta, şifacının kendisiyle geçirdiği süreye, gösterilen 
alakaya, alınan kan miktarına göre şifacıya gelmeye devam etmekte ve tanıdıklarına şifacıyı tavsiye ederken; hekimler karşısında böyle bir tutum geliştirmemektedir.

\section{Sonuç}

Hacamat özü itibariyle Türklerin fethettikleri topraklarda tanıştıkları halklarla kültürleşme sürecinde Türk halk hekimliğine dâhil olmuş kadim bir sağaltma tekniğidir. Türk-İslâm medeniyeti dairesinde, hacamata dair halk hekimliği hadis ve sünnet çerçevesinde düzenlenmiştir. Modern tıp alanında, halkın sağaltma tekniklerinden kanıta dayalı olanlar GT adı altında sınıflandırılmaktadır. Bu bağlamda tüm halk hekimliği uygulamaları, GT kapsamına girmemektedir. Ankara özelinde şifacılara ve hekimlere başvuran hastaların yakınlarından dinledikleri sağalma konulu kişisel deneyim anlatılarını referans alarak şifacı ve/veya hekimlere yöneldiği görülmektedir. Hastalar, sağalmada hacamattan hem kısa vadede hem de uzun vadede fayda görmüşlerdir. Tercihen hekimlere yönelen hastaların hekimin tıp bilgisini, standart ücretlendirmeyi dikkate aldığı; şifacılara yönelen hastaların uygulama özelinde şifacı ve şifa arasında kutsal bir bağ kurduğu, kutsal olandan şifayı talep ettiği kaydedildi. Bununla birlikte cinsiyete bağlı çekincelerin, hacamata eşlik eden dinsel büyüsel pratiklerin de bu tercihte öne çıkarıldığı görüldü. Ekoller arasında hijyen, dinsel ve büyüsel elementler, hangi hastalıklara hacamatın uygulanması gerektiği, hacamatla hastadan alınan kanın miktarına dair beklentiler, kesi derinliği, işlem öncesi ve sonrası sağlık tedbirleri düzeyinde yaklaşımların ve usullerin, hastanın iyilik halini kısa ve uzun vadede tehdit etmeyecek ölçüde farklılaştığı görüldü.

\section{Notlar}

1 DSÖ, bu ayrımı yaparken bir sağlık uygulamasının kültürel kökenini esas almaktadır (WHO, 2013).

2 Bu GETAT uygulamaları, kupa terapisi (hacamat) ve sülüktür. Akapunktur, apiterapi, fitoterapi, hipnoz, homeopati, kayropraktik, larva uygulaması, mezoterapi, proloterapi, osteopati, ozon, refleksoloji, müzikterapi de GETAT uygulamaları arasındadır (CMBS, 2020b).

3 GETAT uygulamaları, Bakanlıkça yetkilendirilmiş ünite ile uygulama merkezlerinde ve ilgili alanda uygulama sertifikası bulunan tabip ve sadece diş hekimliği alanında olmak üzere diş tabibi tarafından yapılabilir. Temel eğitimi bulunan sağlık meslek mensupları merkez ve ünitelerde sertifikalı tabiplere yardımcı olabilirler (CMBS, 2020b).

4 "Türkiye Cumhuriyeti dâhilinde tababet icra ve her hangi surette olursa olsun hasta tedavi edebilmek için tıp fakültesinden diploma sahibi olmak şarttır; Diploması olmadığı hâlde, menfaat temin etmek amacına yönelik olmasa bile, hasta tedavi eden veya tabip unvanını takınan şahıs iki yıldan beş yıla kadar hapis ve bin güne kadar adlî para cezası ile cezalandırılır" (CMBS, 2020a).

5 Hacamat uygulayan şifacılara verilen ceza örnekleri için bakınız: (HT, 2016).

6 Hacamatla ilgili hadis ve sünnetlerin muhtevası üzerine bir değerlendirme için bakınız: (Kaya, 2020, s. 62-83; Aytekin, 2019, s. 207-213).

7 İlgi kaynakta dellak/tellak şeklinde verilen bu mesleğin kadın icracılarına natır adı verilir. Evliya Çelebi'nin meslek erbabını nitelemesi hacamatcılığın Mâlikî, Şâfiî, Hanbelî ve Hanefî mezheplerinin fikhında hacamatcılık hür kişiler için adi meslekler arasında yer alması ile ilgili olduğu düşünülmektedir. Bakınız: (Aytekin 2019: 215-217).

8 “Allah’tan bereket ümit ederek Perşembe günü hacamat yaptırın. Çarşamba, cuma, cumartesi ve pazar günü hacamat yaptırmayın. Özellikle pazartesi veya salı günü hacamat yaptırın. Çünkü Allah bugün Eyüp'e (a.s.) hastalıktan şifa verdi. Çarşamba günü onu hastalığa müptela kılmıştı. Cüzzam ve alaca hastalığı çarşamba günü veya gecesi görülür" dediğini rivayet etmiştir. Yorumlar ve değerlendirmeler için bakınız: (Kaya, 2020, s. 62$83)$. 


\section{Kaynaklar}

Abdülaziz Bey (1995). Osmanlı âdet, merasim ve tabirleri. K. Arısan ve D. Arısan Günay (Haz.). İstanbul: Tarih Vakfi Yurt.

Acıpayamlı, Orhan (1969). Türkiye folklorunda halk hekimliği ve Özellikleri. Ankara Üniversitesi Dil ve Tarih Coğrafya Fakültesi Dergisi, 26(1-2), 1-9.

Acıpayaml, Orhan (1989). Türkiye folklorunda halk hekimliğinin morfolojik ve fonksiyonel yönden incelenmesi. Türk Halk Hekimliği Sempozyumu Bildirileri. Ankara: Kültür Bakanlığı.

Aytekin, M. A. (2019). Nebevî tıp arasında zikredilen hacamatın fikhi hükmü. Necmettin Erbakan Üniversitesi İlahiyat Fakültesi Dergisi, 48, 197-225.

Bendix, R. (1997). in search of authenticity: the formation of folklore studies. Madison: University of Wisconsin.

Blank, T. J. (2007). Examining the transmission of urban legends: Making the case for folklore fieldwork on the internet. Folklore Forum, 37, 15-26.

Boratav, P. N. (2013). 100 Soruda Türk folkloru. Ankara: Bilgesu.

Brady, E. (2012). Folk medicine. The new Encyclopedia of Southern Culture. C. 22. North Carolina: The University of North Carolina. 76-80.

Briggs, C. L. (2012). Toward a new folkloristics of health. Journal of folklore Research, 49(3), 319-345.

Carter, D. (2005). Living in virtual communities: an etnography of human relationship in cyberspace. Information, Communication \& Society. 8, 148-167.

Devellioğlu, F. (2006). Hacâmet. Osmanlıca Türkçe ansiklopedik sözlük lûgat. Ankara: Aydın. 305

Dorson, R. M. (1970). Is there a folk in the city? Journal of American Folklore, 83, 185-216.

Dundes, A. (1965). What is folklore?. The Study of Folklore. New Jersey: Prentice- Hall.

Evliyâ Çelebi (2011). Evliyâ Çelebi seyahatnamesi. Y. Dağlı, S. A. Kahraman ve R. Dankoff (Haz.). C. II, İstanbul, Yapı Kredi.

Goldstein, K. S. (1983). Sahada folklor derleme metotları. A. S. Uysal, (Çev.). Ankara: Başbakanlık.

Guenther, K. M. (2009). The politics of names: rethinking the methodological and ethical significance of naming people, organization and places. Qualitative Research, 9(4), 411-421.

Hicks, G. (1977). Informant anonymity and scientific accuracy: The problem of pseudonyms. Human Organization, 36(2), 214-220.

Hine, C. (2000). Virtual ethnography. London: Sage.

Kaya, H. (2020). Hacamat ile ilgili rivayetler üzerine bir inceleme. Uluslararast Anadolu Sosyal Bilimler Dergisi, 4(2), 62-83.

Kirshenblatt-Gimblett, B. (1996). The electronic vernacular. G. Marcus (Ed.). Connected: Engagements with Media içinde (s. 21-65). University of Chicago, Chicago.

Köşe, A. (1996). Hacamat. TDV İslâm Ansiklopedisi. C. 14. Ankara, TDV, 422.

Manning, P. K ve H. F. Fabrega (1973). The experience of self and body: Health and illness. Ghipas Highlands ve G. Psathas (Ed.). Phenomenological Sociology içinde (s. 251-301). New York: John Wiley.

Murchison, J. (2010). Etnography essentials: Designing, conducting, and presenting your research. San Francisco, Jossey-Bass.

O’Connor, B. B. ve D. J. Hufford (2001). Understanding folk Medicine.. E. Brady (Ed.). Healing Logics: Culture and medicine in modern health belief systems içinde (s. 251-301). Logan: Utah State University. 
Okumuş, M. (2016). Kupa terapisi ve hacamat. Ankara Medical Journal. 16(4), 370-382.

Örnek, S. V. (2000). Türk halk bilimi. Ankara, Kültür Bakanlığı.

Parlakpınar, H. ve S. Polat (2020). Kupa tedavisine genel bir bakış. Geleneksel ve Tamamlayıcı Tip, 3(2), 246-264.

Press, I. (1978). Urban folk medicine: A functional overview. American Anthropologist, 80(1), 71-84.

Qureshi N. A, G. I. Ali,T. S. , T.S. Abushanab, A. T. El-Olemy, M.S. Alqaed, I.S. El-Subai ve A. M. N. Al-Bedah (2017). History of cupping (Hijama): A Narrative Review of Literature. Journal of Integrative Medicine, 15(3), 172-181.

Sert, E., A. A. Sakarya, Ş. B. Yüksel, A. Sert ve M. Z. Kalayc1 (2015). Kupa uygulaması ve kupa uygulamasının klinik araştırmaları. Integrated Tıp, 3(2), 19-25.

Sever, M. (2015). Folk medicine, Folk Healing. Akademik Bakış, 9(17), 181-192.

Thevenot, J. (2014). Thevenot seyahatnamesi. A. Berktay (Çev.). İstanbul, Kitap.

Tokadî Mustafa Efendi (2018). Tahbîzü-l mathûn el-kânûn fít tıb. Mustafa Koç ve E. Tanrıverdi, (Haz). C.1, İstanbul: Türkiye Yazma Eserler Kurumu Başkanlığı.

Turk, J. L. ve E. Allen (1983). Bleeding and cupping. Annual Royal College of Surgeons of England, 65(2), 128-131.

Türkdoğan, O. (1974). Bir kasabada geleneksel tıp ve modern tıp sürekliliği. I. Uluslararası Türk Folklor Semineri Bildirileri. Ankara: Başbakanlık.

Tylor, E. B. (1891a). Primitive culture researches into the development of mythology, philosophy, religion, language, art, and custom. Vol. I, London: John Murray.

Tylor, E. B. (1891b). Primitive culture researches into the development of mythology, philosophy, religion, language, art, and custom. Vol. II, London: John Murray.

Üçer, M. (1989). Sivas’ta folklorik tıp ve bunun modern tıptaki yeri. Türk Halk Hekimliği Sempozyumu Bildirileri. Ankara: Kültür Bakanlığı.

Yoder, D. (1972). Folk medicine. Folklore and Folklife: An introduction. Ed. R. M. Dorson. Chicago: University of Chicago.

\section{Sözlü Kaynaklar}

Bilgin, C. (2020). 1981 doğumlu yükseköğretim mezunu, uzman hekim ile 21 ve 22.05.2020-tarihinde Zoom üzerinden yapılan görüşme.

Çılgı, Y. (2019). 1976 doğumlu, yükseköğretim mezunu, haccam ile 26.10.2019 ve 29.10.2019 tarihinde Ankara' da yapılan görüşme.

D. Karasu (2020). 1976 doğumlu yükseköğretim mezunu, uzman hekim ile 08.05.2020 tarihinde Ankara'da yapılan görüşme.

Demir, S. (2020). 1976 doğumlu, lise mezunu, kamu çalışanı ile 21.03.2020 tarihinde Ankara'da yapılan görüşme.

Ferikli, A. (2020). 1973 doğumlu, yükseköğretim mezunu, uzman hekim ile 19, 20, 21.03.2020 tarihinde Ankara'da yapılan görüşme.

Gültepe, S. (2020). 1978 doğumlu, yükseköğretim mezunu, öğretmen ile 04.12.2020 tarihinde Ankara'da yapılan görüşme.

Kara, M. (2020). 1979 doğumlu yükseköğretim mezunu, uzman hekim ile 02 ve 03.04.2020 tarihinde Ankara' da yapılan görüşme.

Karsl1, S. (2020). 1984 doğumlu, ilköğretim mezunu, haccame ile 05 ve 06.03.2020 tarihinde Ankara' da yapılan görüşme. 
Kılıç, F. (2020). 1980 doğumlu yükseköğretim mezunu, uzman hekim ile 9 ve 10.04.2020 tarihinde Ankara'da yapılan görüşme.

Köksal, A. (2019). 1974 doğumlu, ilköğretim mezunu, haccame ile 21.10.2020 ve 03.11.2019 tarihinde Ankara'da yapılan görüşme.

Mutlu, Ö. (2019). 1967 doğumlu, ilköğretim mezunu, emekli ile 03.11.2019 tarihinde Ankara'da yapılan görüşme.

Usta, N. (2019). 1959 doğumlu, ilköğretim mezunu, ev hanımı ile 10.11.2019 Ankara'da yapılan görüşme.

Öz, N. (2019). 1979 doğumlu, yükseköğretim mezunu, işçi ile 10.11.2019 tarihinde Ankara'da yapılan görüşme.

Kılıç, F. (2020). 1981 doğumlu yükseköğretim mezunu, uzman hekim ile 21 ve 22.05 .2020 tarihinde Zoom üzerinden tarafından yapılan görüşme.

Sel, B. (2019). 1958 doğumlu, ilköğretim mezunu, emekli ile 29.10.2019 tarihinde Ankara'da yapılan görüşme.

Soylu K. (2019). 1972 doğumlu, ilköğretim mezunu, haccam ile15, 16 ve 17.11.2019 tarihinde Ankara'da yapılan görüşme.

Soylu, S. (2019). 1972 doğumlu, ilköğretim mezunu, haccame ile 09.10.2019 ve 10.10.2019 tarihinde Ankara' da yapılan görüşme.

Tik, U. (2019). 1968 doğumlu, yükseköğretim mezunu, uzman hekim ile 31.10 .2019 tarihinde Ankara'da yapılan görüşme.

Tos, T. (2020). 1974 doğumlu yükseköğretim mezunu, uzman hekim ile 26 ve 27.03 .2020 tarihinde Ankara'da yapılan görüşme.

Uslu, M. (2019). 1994 doğumlu, ilköğretim mezunu, haccame ile 12, 13 ve 26.12 .2019 tarihinde Ankara'da yapılan görüşme.

Veren, E. (2020). 1965 doğumlu, yükseköğretim mezunu, emekli ile 29.05.2020 tarihinde Zoom üzerinden yapılan görüşme.

Yolcu, L. (2019). 1969 doğumlu, ilköğretim mezunu, emekli ile 03.11.2019 tarihinde Ankara'da yapılan görüşme.

\section{Elektronik Kaynaklar}

CMBS (2020a). Tababet ve Şuabatı san'atlarının tarzı icrasına dair kanun. Cumhurbaşkanlığı mevzuat bilgi sistemi. https://www.mevzuat.gov.tr/mevzuat?MevzuatNo=1219\&MevzuatTur=1\&Mevzua tTertip=3 (Erişim tarihi 22.11.2020).

CMBS (2020b). GETAT yönetmeliği. Cumhurbaşkanllğı mevzuat blgi sistemi. https://www. mevzuat.gov.tr/mevzuat?MevzuatNo=20164\&MevzuatTur=7\&MevzuatTertip=5 (Erişim tarihi 22.11.2020).

WHO (2013). WHO traditional medicine strategy 2013-2023. https://www.who.int/health-topics/ traditional-complementary-and-integrative-medicine\#tab=tab_1. (Erişim tarihi 23.06.2020).

WHO (2000). General Guidelines for Methodologies on Research and Evaluation of Traditional Medicine. https://apps.who.int/iris/bitstream/handle/10665/66783/WHO_EDM_TRM_2000.1.pdf ? sequence $=1 \&$ is Allowed $=$. (Erişim tarihi 23.06.2020).

WHO (2008). Beijing declaration. https://www.who.int/medicines/areas/traditional /TRM BeijingDeclarationEN.pdf?ua=1. (Erişim tarihi 15.10.2020).

HT (2016). Ruhsatsız hacamat yaptıkları iddia edilen çifte, 10'ar ay hapis cezası verildi. Haber Türk. https:/www.haberturk.com/gundem/haber/1336705-ruhsatsiz-hacamat-yaptiklari iddia-edilencifte-10ar-ay-hapis-cezasi-verildi. (Erişim tarihi 17. 11.2020). 


\section{ETIK KURUL BILDİRIMI}

Bu makaleye ilişkin olarak;

Bartın Üniversitesi

Sosyal ve Beşeri Bilimleri Etik Kurulu'nun 30.12.2020 tarih 25 sayılı ve Kurul Başkanı Prof. Dr. Aslı Yazıcı'nın imzasıyla dergimize iletilmiş olan belgeyle etik açıdan oybirliğiyle olumlu görüş bildirilmiştir.

Söz konusu belge dergi yönetimince arşivlenmiştir.

\section{folklor/edebiyat dergisi}

